\title{
Synthesis and characterization of Ag-doped p-type ZnO nanowires
}

\author{
Guoping Wang • Sheng Chu $\cdot$ Ning Zhan • \\ Huimei Zhou • Jianlin Liu
}

Received: 13 January 2011 / Accepted: 8 March 2011 / Published online: 31 March 2011

C) Springer-Verlag 2011

\begin{abstract}
P-type $\mathrm{ZnO}$ nanowires with silver (Ag) doping were synthesized via a chemical vapor deposition process. The incorporation of $\mathrm{Ag}$ was confirmed by selected-area energy-dispersive x-ray spectroscopy. The formation of acceptor states was demonstrated by temperature and excitation power-dependent photoluminescence measurements. Characterization of field-effect transistors using Ag-doped $\mathrm{ZnO}$ nanowires as channels showed p-type conductivity of the nanowires with a hole concentration of $4.9 \times 10^{17} \mathrm{~cm}^{-3}$ and a carrier mobility of approximately $0.18 \mathrm{~cm}^{2} \mathrm{~V}^{-1} \mathrm{~s}^{-1}$.
\end{abstract}

$\mathrm{ZnO}$, a wide-band-gap semiconductor with large exciton binding energy of $60 \mathrm{meV}$ at room temperature $[1,2]$, is a promising candidate for optoelectronic devices such as blue-light emitting diodes [3,4], ultraviolet laser diodes $[5,6]$, and photodiodes [7, 8]. It is well known that one of the biggest challenges toward good $\mathrm{ZnO}$-based optoelectronic devices is the difficulty of reliably fabricating p-type $\mathrm{ZnO}$ due to the self-compensating effect from native defects (for example, oxygen vacancy $V_{o}$ and zinc interstitial $\mathrm{Zn}_{\mathrm{i}}$ ) and/or $\mathrm{H}$ incorporation [9]. There has already been a great deal of efforts on the fabrication of p-type $\mathrm{ZnO}$ films by doping group I (Na, Ag) $[10,11]$ and group $\mathrm{V}$ elements (N, P, As, Sb) [12-15] as p-type dopants. In contrast, there have been only a few reports on p-type $\mathrm{ZnO}$ nanowires (doped with N, P, and Na) [16-18]. Recently, researchers are interested in developing optoelectronic devices based on $\mathrm{ZnO}$ nanowires such as biosensors, ultra-

G. Wang $\cdot$ S. Chu $\cdot$ N. Zhan $\cdot$ H. Zhou $\cdot$ J. Liu $(\bowtie)$

Quantum Structures Laboratory, Department of Electrical Engineering, University of California at Riverside, Riverside, CA 92521, USA

e-mail: jianlin@ee.ucr.edu violet detectors, ultraviolet light emitting diodes, and electrically driven nanowire lasers. The growth of p-type $\mathrm{ZnO}$ nanowires with good stability will be an essential step for the applications of nanowires in nanoelectronics and optoelectronics. Ag, a group Ib element, was predicted to be an acceptor in $\mathrm{ZnO}$ when incorporated into substitutional $\mathrm{Zn}$ sites [19]. Indeed, researchers experimentally demonstrated reliable fabrication of p-type $\mathrm{ZnO}$ thin films doped with $\mathrm{Ag}$ on sapphire substrate [11] with hole concentrations up to $6 \times 10^{17} \mathrm{~cm}^{-3}$ and also demonstrated the possibility of achieving Ag-doped p-type $\mathrm{ZnO}$ nanowires [20, 21]. However, the electrical and optical properties of singlecrystalline Ag-doped $\mathrm{ZnO}$ nanowires have not been comprehensively studied yet. In this paper, we report the synthesis and characterization of single-crystalline Ag-doped p-type $\mathrm{ZnO}$ nanowires. P-type $\mathrm{ZnO}$ nanowires were grown from a mixture of zinc powder and silver (I) oxide using chemical vapor deposition (CVD). The incorporation of Ag was confirmed by selected-area energy-dispersive $\mathrm{x}$ ray spectroscopy (SAEDX) and photoluminescence (PL) studies. Single-nanowire field effect transistors were subsequently fabricated, which exhibited hole conduction channels, confirming the p-type conductivity of the Ag-doped $\mathrm{ZnO}$ nanowires.

The growth of nanowires was performed at $730^{\circ} \mathrm{C}$ for 15 minutes with a gas mixture, containing $600 \mathrm{sccm}$ nitrogen and $300 \mathrm{sccm}$ argon/oxygen (99.5:0.5). The mixture source of zinc powder and silver (I) oxide (1:2 in mass) in a quartz boat was placed in the center of the quartz tube. The silicon substrate was closely attached to the quartz boat on the downstream side.

Figures 1(a) and (b) show the scanning electron microscopy (SEM) image of the nanowires from the top and regular transmission electron microscopy (TEM) image of an individual nanowire, respectively. The length 
Fig. 1 (a) Top-view SEM image of as-grown $\mathrm{ZnO}$ nanowires. (b) TEM image of a single $\mathrm{ZnO}$ nanowire.

(c) HR-TEM image of the nanowire. Inset images are (top) the SAED pattern and (bottom) a Fourier-filtered HR-TEM image. SAED pattern indicates the single-crystalline characteristic of the nanowire. The lattice spacing between two atomic layers is measured to be $0.529 \mathrm{~nm}$. (d) SAEDX spectrum of the individual nanowire shown in $(\mathbf{b})$
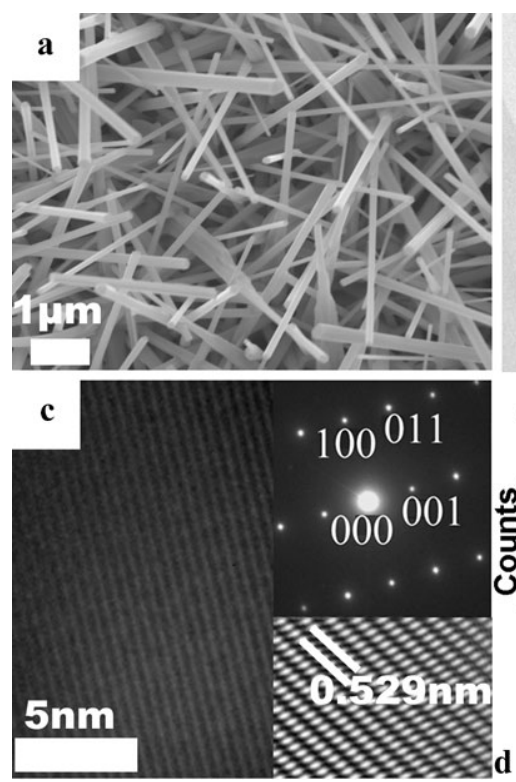

b

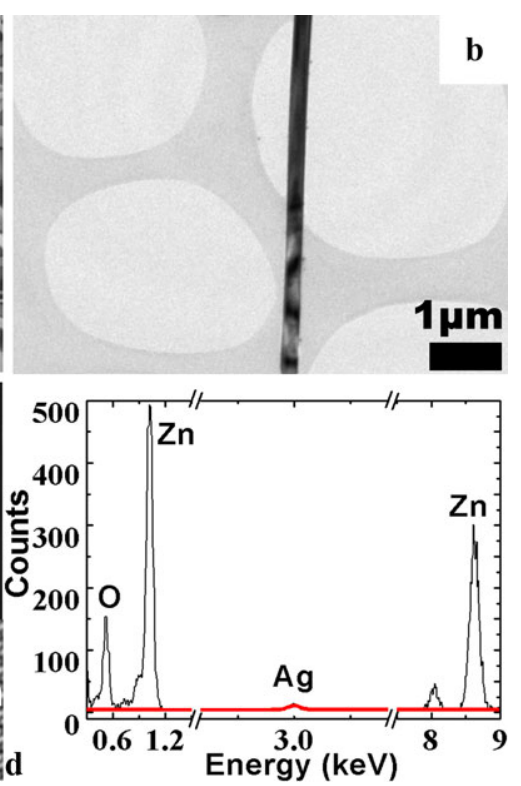

and diameter of the $\mathrm{ZnO}$ nanowires are on average $5 \mu \mathrm{m}$ and $250 \mathrm{~nm}$, respectively. The single-crystalline nature of the $\mathrm{ZnO}$ nanowires is revealed by high-resolution TEM (HR-TEM) image (Fig. 1(c)) and the selected area electron diffraction (SAED) pattern analysis (the top inset of Fig. 1(c)). The lattice constant is determined to be $0.529 \mathrm{~nm}$ as shown in the bottom inset of Fig. 1(c), which also indicates the [001] growth direction of the nanowire. Figure 1(d) presents the SAEDX spectrum of the individual nanowire shown in Fig. 1(b), confirming the incorporation of $\mathrm{Ag}$. The average atomic content of $\mathrm{Ag}$ was estimated to be $\sim 0.1$ atom $\%$.

To confirm the formation of acceptor levels by Ag doping, low-temperature PL measurements were performed with a $325 \mathrm{~nm} \mathrm{He}-\mathrm{Cd}$ laser operated at $89 \mu \mathrm{W}$. The laser beam impinged against the sample surface with an angle of approximately $60^{\circ}$. The excited PL emission was measured with an Oriel monochromator, which was aligned perpendicular to the sample surface. Figure 2(a) shows the temperature-dependent PL spectra of the Ag-doped sample at the temperatures ranging from 14 to $300 \mathrm{~K}$. The emissions at $3.328 \mathrm{eV}, 3.376 \mathrm{eV}, 3.277 \mathrm{eV}$, and $3.226 \mathrm{eV}$ under the temperature of $14 \mathrm{~K}$ can be assigned to be neutralacceptor-bound exciton $\left(\mathrm{A}^{\circ} \mathrm{X}\right)$, ground state of $\mathrm{A}$ free exciton $\left(\mathrm{FX}_{\mathrm{A}}^{n=1}\right)$, free electron to acceptor level (FA) and donoracceptor pair (DAP) transitions, respectively [22]. The appearance of different states of free excitons reflects the good optical property of the $\mathrm{ZnO}$ nanowires. The DAP emission at $3.226 \mathrm{eV}$ shows a slightly progressive blueshift with an increase of temperature from 14 to $100 \mathrm{~K}$, which is a result of thermal ionization of donors at higher temperatures and has been consistently reported as a typical characteristic of the DAP transition for $\mathrm{ZnO}[23,24]$.
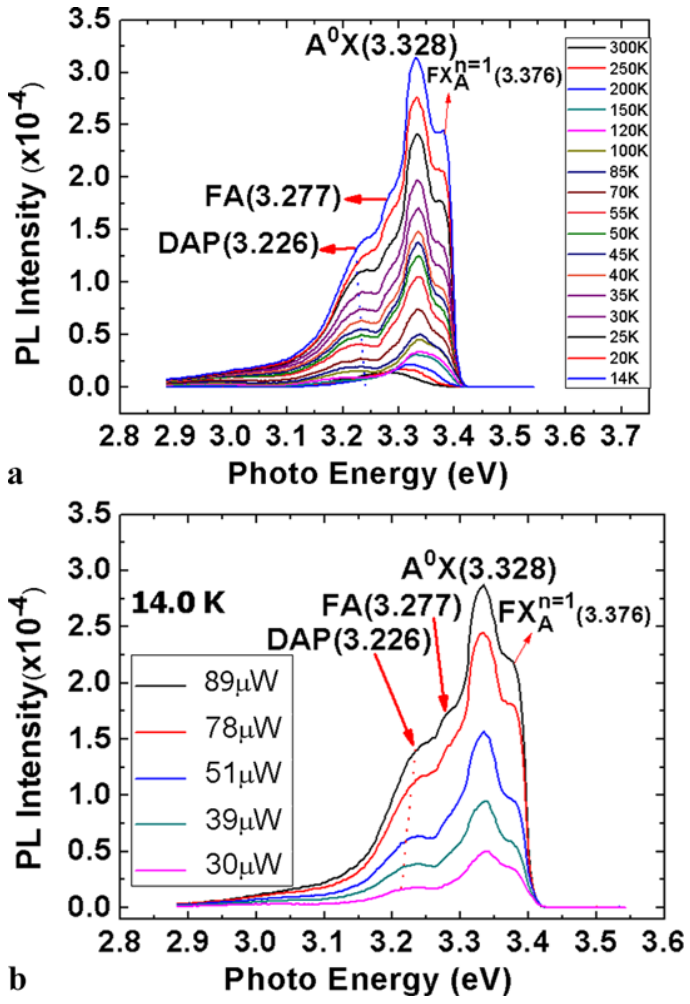

Fig. 2 Low-temperature PL spectra of (a) Ag-doped $\mathrm{ZnO}$ nanowires at temperatures ranging from 14 to $300 \mathrm{~K}$. (b) Ag-doped $\mathrm{ZnO}$ nanowires under different excitation power at $14 \mathrm{~K}$

In Fig. 2(b), the excitation power-dependent PL measurement results show the evolution of the DAP emission. The experiments were conducted at $14 \mathrm{~K}$ with different laser excitation power. With a decrease of the excitation power, the $3.226 \mathrm{eV}$ emission exhibits an evident redshift. The peak 
energy of such transition is given by the following equation [12]:

$E_{\mathrm{DAP}}=E_{\text {gap }}-E_{\mathrm{D}}-E_{\mathrm{A}}+e^{2} / 4 \pi \varepsilon R_{\mathrm{DAP}}$

where $E_{\mathrm{DAP}}, E_{\mathrm{gap}}, E_{\mathrm{D}}, E_{\mathrm{A}}, e, \varepsilon$ and $R_{\mathrm{DAP}}$ are DAP transition energy, band gap energy, donor ionization energy, acceptor ionization energy, elementary charge constant, dielectric constant, and donor-acceptor pair distance, respectively. As the excitation intensity (power/area) decreases, the number of photo excited donor-acceptor pairs decreases, resulting in a longer donor-acceptor pair distance $\left(R_{\mathrm{DAP}}\right)$. Therefore, a DAP transition shifts to a lower energy.

Based on the FA peak position in Fig. 2(a), the acceptor binding energy $\left(E_{\mathrm{A}}\right)$ at $14 \mathrm{~K}$ can be calculated with [25]:

$E_{\mathrm{A}}=E_{\mathrm{gap}}-E_{\mathrm{FA}}+k_{\mathrm{B}} T / 2$

where $E_{\mathrm{FA}}$ is the temperature-dependent transition with an energy of $3.277 \mathrm{eV}$ at $14 \mathrm{~K}, E_{\text {gap }}$ is the intrinsic band gap energy, which is approximately equal to $3.437 \mathrm{eV}$ at $14 \mathrm{~K}$, and $k_{\mathrm{B}}$ is Boltzmann constant. Thus, the value of $E_{\mathrm{A}}$ is calculated to be $0.158 \mathrm{eV}$.

In order to further prove p-type conductivity of the Agdoped $\mathrm{ZnO}$ nanowires, electrical measurements on backgated nanowire field effect transistors (NWFETs) were carried out. ZnO NWFETs were fabricated by standard photolithography. Ag-doped $\mathrm{ZnO}$ nanowires were first dispersed in isopropyl alcohol, and subsequently transferred to a $\mathrm{p}^{+}$-silicon wafer with a $300 \mathrm{~nm}$ thick silicon oxide on the surface. Microcontact windows were defined on the ends of the nanowires, and then the $\mathrm{Ni} / \mathrm{Au}$ electrodes were formed by e-beam deposition and subsequent lift-off. The $\mathrm{p}^{+}$-silicon substrate served as the back-gate electrode of the transistor. The inset in Fig. 3(a) shows the SEM image of the NWFET. The drain current $\left(I_{\mathrm{d}}\right)$ versus gate voltage $\left(V_{\mathrm{g}}\right)$ curve under a drain bias $\left(V_{\mathrm{d}}\right)$ of $10 \mathrm{~V}$ and $I_{\mathrm{d}}$ versus $V_{\mathrm{d}}$ curves under different gate voltages are shown in Fig. 3(a) and Fig. 3(b), respectively. The drain current decreases as the increase of the gate voltage from $-30 \mathrm{~V}$ to $30 \mathrm{~V}$, suggesting that the Ag-doped $\mathrm{ZnO}$ nanowires exhibit p-type behavior. The hole concentration $(\mathrm{P})$ in nanowires can be estimated by using the following equation [26]:

$P=\left(\frac{V_{\mathrm{th}}}{q}\right) \times\left(\frac{2 \pi \varepsilon_{r} \varepsilon_{0}}{\ln (4 h / d)}\right) \times\left(\frac{1}{\pi d^{2} / 4}\right)$

where $\varepsilon_{r}, \varepsilon_{0}, h, d, V_{\text {th }}$, and $q$ are the effective dielectric constant $\left(\varepsilon_{r}=3.9\right.$ for $\left.\mathrm{SiO}_{2}\right)$, dielectric constant of vacuum, thickness of dielectric layer $(300 \mathrm{~nm})$, nanowire diameter $(250 \mathrm{~nm})$, threshold voltage of the ZnO NWFET ( $28 \mathrm{~V})$ and elementary charge constant, respectively. From (3), the
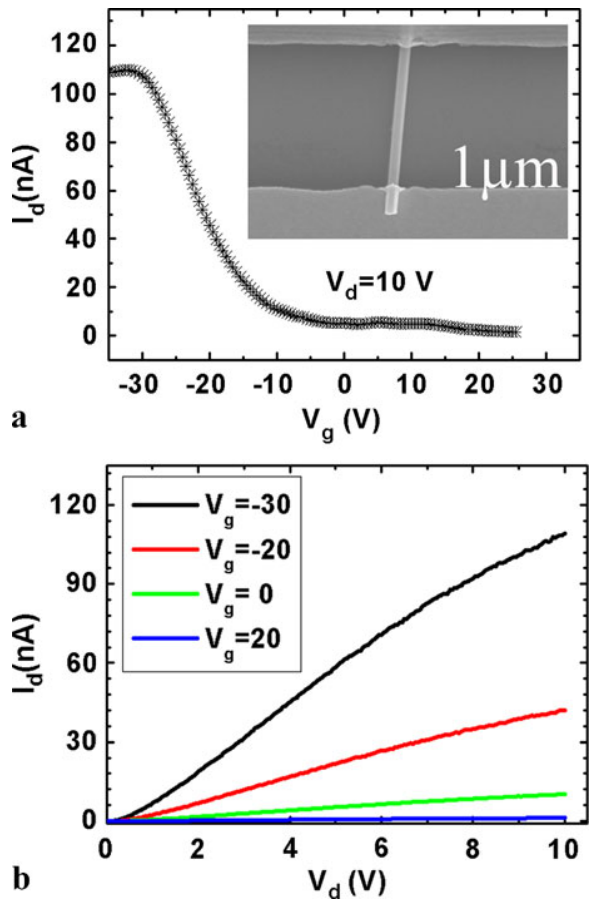

Fig. 3 (a) $I_{\mathrm{d}}-V_{\mathrm{g}}$ curve of the $\mathrm{ZnO}$ NWFET under $V_{\mathrm{d}}=10 \mathrm{~V}$. Inset shows the SEM image of the NWFET. (b) $I_{\mathrm{d}}-V_{\mathrm{d}}$ curves of the $\mathrm{ZnO}$ NWFET recorded at different gate voltages

hole concentration is calculated to be $4.9 \times 10^{17} \mathrm{~cm}^{-3}$. The mobility can be calculated by using [26]:

$\mu=\left(\frac{\mathrm{d} l}{\mathrm{~d} V_{\mathrm{g}}}\right) \times\left(\frac{\ln \left(\frac{4 h}{d}\right)}{2 \pi \varepsilon_{r} \varepsilon_{0}}\right) \times\left(\frac{L}{V_{\mathrm{d}}}\right)$

where $\mu, L$, and $V_{\mathrm{d}}$ is the mobility, channel length $(\sim 3 \mu \mathrm{m}$ in the NWFET) and drain bias $(10 \mathrm{~V})$, respectively. $\frac{\mathrm{d} l}{\mathrm{~d} V_{\mathrm{g}}}=$ 7.16e-009 A/V can be extrapolated from the linear region of the $I_{\mathrm{d}}-V_{\mathrm{g}}$ curve. From (4), the hole mobility is calculated as approximately $0.18 \mathrm{~cm}^{2} \mathrm{~V}^{-1} \mathrm{~s}^{-1}$.

In summary, Ag-doped $\mathrm{ZnO}$ nanowires have been grown via CVD process. The PL spectrum of the Ag-doped nanowires shows an Ag-related peak at $3.328 \mathrm{eV}$ at $14 \mathrm{~K}$, which can be attributed to neutral-acceptor-bound excitons $\left(\mathrm{A}^{\circ} \mathrm{X}\right)$. Temperature- and excitation power-dependent PL spectra confirm shallow acceptor level of $0.158 \mathrm{eV}$. The electrical measurement results suggest that the conductivity of Ag-doped $\mathrm{ZnO}$ nanowires is $p$-type and the hole mobility is approximately $0.18 \mathrm{~cm}^{2} \mathrm{~V}^{-1} \mathrm{~s}^{-1}$. After 5 months (by the time of the publication this paper), however, originally ptype Ag-doped $\mathrm{ZnO}$ nanowires turned into n-type judging from NWFET measurements. Therefore, long-term p-type stability of $\mathrm{Ag}$-doped $\mathrm{ZnO}$ nanowires is still an issue.

Acknowledgement This research was partly supported by NSF (EECS-0900978). 


\section{References}

1. E.O. Kane, Phys. Rev. B 18, 6849 (1978)

2. C. Klingshirn, Phys. Status Solidi B 244, 3027 (2007)

3. D.C. Look, Mater. Sci. Eng. B 80, 383 (2001)

4. S. Chu, J.H. Lim, L.J. Mandalapu, Z. Yang, L. Li, J.L. Liu, Appl. Phys. Lett. 92, 152103 (2008)

5. S.F. Yu, C. Yuan, S.P. Lau, W.I. Park, G. Yi, Appl. Phys. Lett. 84, $3241(2004)$

6. L.K. van Vugt, S. Ruhle, D. Vanmaekelbergh, Nano Lett. 6, 2707 (2006)

7. L.J. Mandalapu, F.X. Xiu, Z. Yang, D.T. Zhao, J.L. Liu, Appl. Phys. Lett. 88, 112108 (2006)

8. L.J. Mandalapu, Z. Yang, F.X. Xiu, D.T. Zhao, J.L. Liu, Appl. Phys. Lett. 88, 092103 (2006)

9. C.G. Van de Walle, Phys. Rev. Lett. 85, 1012 (2000)

10. S.S. Lin, H.P. He, Y.F. Lu, Z.Z. Ye, J. Appl. Phys. 106, 093508 (2009)

11. H.S. Kang, B.D. Ahn, J.H. Kim, G.H. Kim, S.H. Lim, H.W. Chang, S.Y. Lee, Appl. Phys. Lett. 88, 202108 (2006)

12. D.K. Hwang, H.S. Kim, J.H. Lim, J.Y. Oh, J.H. Yang, S.J. Park, K.K. Kim, D.C. Look, Y.S. Park, Appl. Phys. Lett. 86, 151917 (2005)

13. K.K. Kim, H.S. Kim, D.K. Hwang, J.H. Lim, S.J. Park, Appl. Phys. Lett. 83, 63 (2003)

14. T.S. Jeong, M.S. Han, C.J. Youn, Y.S. Park, J. Appl. Phys. 96, 175 (2004)
15. F.X. Xiu, Z. Yang, L.J. Mandalapu, D.T. Zhao, J.L. Liu, W.P. Beyermann, Appl. Phys. Lett. 87, 152101 (2005)

16. B. Xiang, P.W. Wang, X.Z. Zhang, S.A. Dayeh, D.P. Aplin, C. Soci, D.P. Yu, D.L. Wang, Nano Lett. 7, 323 (2007)

17. G.D. Yuan, W.J. Zhang, J.S. Jie, X. Fan, J.A. Zapien, Y.H. Leung, L.B. Luo, P.F. Wang, C.S. Lee, S.T. Lee, Nano Lett. 8, 2591 (2008)

18. W. Liu, F.X. Xiu, K. Sun, Y.H. Xie, K.L. Wang, Y. Wang, J. Zou, Z. Yang, J.L. Liu, J. Am. Chem. Soc. 132, 2498 (2010)

19. Y. Kanai, Jpn. J. Appl. Phys. 30, 2021 (1991)

20. Y.W. Song, K. Kim, J.P. Ahn, G.E. Jang, S.Y. Lee, Nanotechnology 20, 275606 (2009)

21. M.A. Thomas, J.B. Cui, J. Phys. Chem. Lett. 1, 1090 (2010)

22. Ü. Özgür, Ya.I. Alivov, C. Liu, A. Teke, M.A. Reshchikov, S. Doğan, V. Avrutin, S.-J. Cho, H. Morkoç, J. Appl. Phys. 98, 041301 (2005)

23. K. Tamura, T. Makino, A. Tsukazaki, M. Sumiya, S. Fuke, T. Furumochi, M. Lippmaa, C.H. Chia, Y. Segawa, H. Koinuma, M. Kawasaki, Solid State Commun. 127, 265 (2003)

24. K. Thonke, T. Gruber, N. Teofilov, R. Schonfelder, A. Waag, R. Sauer, Physica B 308, 945 (2001)

25. Y.R. Ryu, T.S. Lee, H.W. White, Appl. Phys. Lett. 83, 87 (2003)

26. R. Martel, T. Schmidt, H.R. Shea, T. Hertel, Ph. Avouris, Appl. Phys. Lett. 73, 2447 (1998) 